Original Research

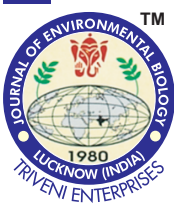

DOI : http://doi.org/10.22438/jeb/40/2/MRN-801

\title{
Protective effect of phytochemicals on the triclosan- induced DNA damage
}

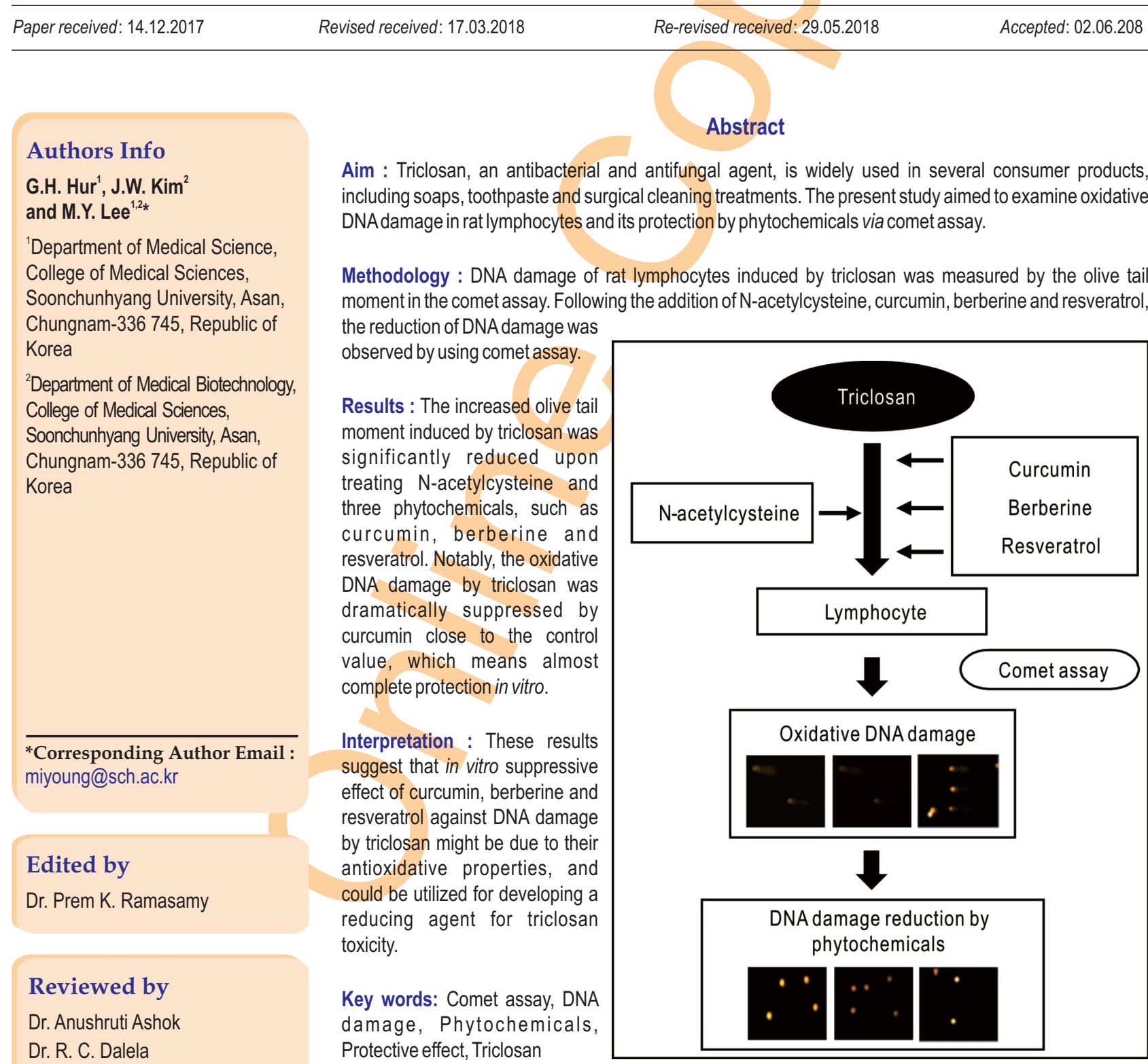

How to cite: Hur, G.H., J.W. Kim and M.Y. Lee : Protective effect of phytochemicals on the triclosan-induced DNAdamage. J. Environ. Biol., 40, 165-169 (2019). 


\section{Introduction}

Triclosan $\left(\mathrm{C}_{12} \mathrm{H}_{7} \mathrm{Cl}_{3} \mathrm{O}_{2}\right)$, an antibacterial and antifungal agent, is widely used in several consumer products, including soaps, toothpaste and surgical cleaning treatments (Ao et al., 2017; Rattan et al., 2017). However, the adverse health effects of triclosan (Yueh et al., 2014; Marshall et al., 2015) includes high risk allergic sensitization, cardiovascular disease, as well as estrogenic and androgenic property (Szychowski et al., 2016; Datta et al., 2017; Teplova et al., 2017). Recently, triclosan is considered as a "contaminant of emerging concern", which means that it is under investigation for public health risk. Triclosan is not commonly monitored in the environment but has potential to enter the environment and cause known or suspected adverse ecological and (or) human health effects (Halden, 2014). Triclosan shows varied toxicity depending on its dose. High dose of triclosan appears as a biocide with multiple cytoplasmic and membrane targets (Ajao et al., 2015; Weatherly et al., 2015; Shim et al., 2016). However, triclosan acts as a bacteriostatic agent in commercial products, inhibiting synthesis of microbial fatty acid at low doses. When low dose triclosan binds to microbial enoylacyl carrier protein reductase (ENR), the binding affinity of ENR for nicotinamide adenine dinucleotide increases. Thus, a ternary complex of ENR-NAD -triclosan in bacteria might inhibit fatty acid synthesis in bacteria. In human, however, triclosan is suggested to affect with different reaction mechanism as ENR enzyme is absent in humans. The mode of action of triclosan in human has not been elucidated yet (Dann and Hontela, 2011; Verslycke et al., 2016; Ruszkiewicz et al., 2017).

Comet assay, also referred to as single cell gel electrophoresis, has been extensively used for the detection of DNA damages and repair at individual cell levels. Comet assay is a simple, sensitive and fast technique for assessing DNA strand breaks, alkali-labile sites, DNA cross-links and base-pair damages (Nandhakumar et al., 2011). The applications of comet assay range from DNA damage in specific genomic sequences within eukaryotic cells to massive human biomonitoring.

A wide variety of phytochemicals, named polyphenols and alkaloids, have been known to provide beneficial effects for human through notable antioxidant activity. Phytochemicals have been reported to diminish oxidative stress and the relevant risk of chronic diseases (Sreelatha et al., 2012). Information on the toxic effect of triclosan on the lymphocyte DNA and the ameliorative capability of phytochemicals against triclosan toxicity has not been fully addressed yet. In light of the above, the ameliorative effect of $\mathrm{N}$-acetylcysteine and phytochemicals such as curcumin berberine and resveratrol on the oxidative DNA damage by triclosan was examined in this study.

\section{Materials and Methods}

Preparation of lymphocytes: Male Sprague-Dawley rats (Orient Bio Inc. Seongnam, Korea), weighing approximately $250 \mathrm{~g}$, were maintained in an experimental room under controlled conditions of temperature $\left(22 \pm 2^{\circ} \mathrm{C}\right)$ humidity $(50 \pm 10 \%)$, and a 12-hour light/dark cycle. Five rats were anesthetized and whole blood was collected into EDTA-containing tubes. A $200 \mu \mathrm{l}$ of fresh whole blood was added to $800 \mu$ l of phosphate-buffered saline (PBS) and layered onto $200 \mu \mathrm{l}$ of Histopaque 1077 (SigmaAldrich, St. Louis, MO). After centrifugation at $1,450 \mathrm{rpm}$ for 5 $\mathrm{min}$ at room temperature, the lymphocytes were collected from the buffy-coat layer and washed with PBS. Comet assay using rat blood was conducted with the approval of the Animal Research Ethics Committee at Soonchunhyang University (approval number: SCH15-0007).

Lymphocyte treatment : Triclosan and stock solution was made by dissolving triclosan in DMSO. N-acetylcysteine (NAC) and three phytochemicals such as curcumin, resveratrol and berberine were dissolved in DMSO and then diluted with PBS. They were directly added to the lymphocytes which were treated for 30 min at $37^{\circ} \mathrm{C}$ before triclosan treatment. Phosphate buffered saline was treated to lymphocytes as a control.

Determination of DNA damage by comet assay : The alkaline comet assay was performed following the method of Singh et al. (1988) with slight modification (Kim et al., 2017) to evaluate triclosan-induced DNA damage and determine the ameliorative effect of selected phytochemicals. The lymphocytes were mixed with $75 \mu \mathrm{l}$ of $0.7 \%$ low-melting-point agarose and placed onto slides pre-coated with $1 \%$ normal-melting-point agarose, which was then allowed to solidify over $30 \mathrm{~min}$ at $4^{\circ} \mathrm{C}$. Once solidified, the slides were further covered with $100 \mu \mathrm{l}$ of $0.7 \%$ low-meltingpoint agarose. After the last applied agarose had been solidified, the slides were immersed in lysis solution $(2.5 \mathrm{M} \mathrm{NaCl}, 100 \mathrm{mM}$ EDTA, $10 \mathrm{mM}$ Tris, $1 \%$ Triton X-100 and 10\% DMSO) for more than one hour at $4^{\circ} \mathrm{C}$ in dark. To unwind the DNA, the slides were placed in an electrophoresis tank containing electrophoresis buffer [300 mM NaOH and $10 \mathrm{mM} \mathrm{Na}{ }_{2}$ EDTA (pH 13.0)] for $20 \mathrm{~min}$ at $4^{\circ} \mathrm{C}$. Electrophoresis was performed at $25 \mathrm{~V} / 300 \mathrm{~mA}$ for $20 \mathrm{~min}$ at $4^{\circ} \mathrm{C}$. The slides were washed with neutralizing buffer $(0.4 \mathrm{M}$ Tris $\bullet \mathrm{HCl} \mathrm{pH} \mathrm{7.5)} \mathrm{three} \mathrm{times} \mathrm{for} 5 \mathrm{~min}$ at $4^{\circ} \mathrm{C}$ and fixed with crude ethanol for $5 \mathrm{~min}$. Slides were air dried for $15 \mathrm{~min}$ and stored in a slide box at $4^{\circ} \mathrm{C}$.

Image analysis : The slides were stained with ethidium bromide $(50 \mu \mathrm{M})$ and the fluorescence was measured using a fluorescence microscope (Leica, Wetzlar, Germany) in dark condition and viewed with a CCD camera (Hitachi, Japan). The captured image was analyzed using Komet 5.5 software (Kinetic Imaging, UK). DNA damage was quantified via comet assay, wherein the olive tail moment was calculated by the following formula: (Tail. mean-Head.mean) x Tail\% DNA/ 100. A total of 100 lymphocytes were randomly captured and the comets were examined from each slide. All measurements were made in duplicate and performed from three independent experiments.

Statistical analysis: All comet data were analyzed using the SPSS package for Windows version 13 (SPSS Inc., Chicago, IL). The olive tail moments, values of DNA damage, from each treatment were compared with each other by one way analysis of variance (ANOVA) followed by Duncan's Multiple Range Test. $p<$ 0.05 was considered significant. 


\section{Results and Discussion}

The triclosan-induced DNA damage occurred in a dosedependent manner. All the concentrations of triclosan $(6,9,12$ and $\left.15 \mu \mathrm{g} \mathrm{ml}^{-1}\right)$ induced statistically significant DNA damage $(p<$ 0.05 ). The olive tail moment at $6 \mu \mathrm{g} \mathrm{ml}^{-1}$ triclosan was about $19.2 \pm$ 4.77, whereas that of PBS-treated control was about $1.3 \pm 0.32$, indicating approximately a 14 -fold increase in DNA damage with 6 $\mu \mathrm{gl}^{-1}$ triclosan assessed by olive tail moment (Fig. 1). The popular antioxidants, $\mathrm{N}$-acetylcysteine (NAC) suppressed DNA damage caused by triclosan in lymphocytes as shown in Fig. 2 (A). NAC has been clinically used for diseases including cardiovascular disease, sickle cell anemia and inflammation. The efficacy of NAC is due to its nucleophilicity and antioxidant property ( De Flora et al., 2001).

Lymphocytes were pre-treated with $\mathrm{N}$-acetylcysteine at three concentrations $\left(1,2\right.$ and $\left.3 \mu \mathrm{g} \mathrm{m}^{-1}\right)$, and DNA damage was induced by exposing the lymphocytes to $6 \mathrm{\mu g} \mathrm{ml}^{-1}$ triclosan. The DNA damage in the NAC pre-treated group was notably inhibited in a concentration-dependent manner. NAC, derived from reduced glutathione, seems to act as a direct ROS scavenger (Sadowska et al., 2007). The results show that triclosan induced oxidative DNA breakage in lymphocytes, but the oxidative DNA damage was blunted upon application of NAC, probably due to the antioxidative capability of NAC.

Next, the protective effect of curcumin, resveratrol and berberine on triclosan-induced oxidative DNA damage was studied. The herbal phytochemicals showed significant suppressive effects on triclosan toxicity, probably due to their function as scavengers and quenchers against free radical (Gao et al., 2017). Phytochemicals have been utilized as complementary and alternative agents to conventional pharmacological therapeutics (Grabacka et al., 2014; Park and Jang, 2017). They are involved in a range of efficacies from inhibiting cancer cell proliferation to protecting against oxidative damage that prevents chronic diseases such as heart disease, hypertension, diabetes and multiple cancers. Moreover, they act as reducer of cytochrome $\mathrm{P}_{450}$ enzyme system in the liver and antiinflammatory chemical, carbohydrate metabolism promoter and immune system modulator (Ko et al., 2016; Dhupal et al., 2017; Nilnumkhum et al., 2017).

Curcumin is the principal curcuminoid of turmeric, and possess anti-inflammatory, antioxidant, anti-cancer and neuro protective properties (Derochette et al., 2013). Curcumin has been reported to be an effective scavenger of reactive oxygen species and reactive nitrogen species in vitro. Berberine is an isoquinoline alkaloid present in Berberis. It is known for its antibacterial, anti-aging and anticancer activity (Kim et al., 2016). Resveratrol,3,5,4'-trihydroxy-trans-stilbene, is one of the phytoalexin induced by external stimuli including pathogen in several plants including grape. There is no conclusive human evidence for an effect of resveratrol on heart disease, cancer and metabolism. However, resveratrol has been reported to have numerous positive health effects including the anti- inflammatory, anti-oxidative and anti-cancer effect in various cancer cells, mice and rats (Rauf et al., 2017).

The protective effect of curcumin on triclosan-induced oxidative DNA damage is shown in Fig. $2 \mathrm{~B}$. The olive tail moment from all curcumin-treated group significantly decreased close to the level of the control group. The olive tail moment with 1,5 and 7 $\mu \mathrm{g} \mathrm{m}^{-1}$ curcumin treatment was about $6 \pm 0.3,4.4 \pm 1.84$ and $4.2 \pm$ 0.41 , respectively, while that at $6 \mu \mathrm{g} \mathrm{m}^{-1}$ triclosan was $41.8 \pm 5.55$. Fig. $2 \mathrm{C}$ indicates the inhibitory effect of berberine on triclosaninduced oxidative DNA damage. The olive tail moment of the berberine-treated group significantly reduced down to the level of control group. The olive tail moment with 1,5 and $7 \mu \mathrm{g} \mathrm{ml}^{-1}$ berberine application was about $11.9 \pm 1.32,16.2 \pm 4.05$ and $11.5 \pm 4.31$, respectively, while that at $6 \mu \mathrm{g} \mathrm{ml}^{-1}$ triclosan was $41.8 \pm 5.75$ (Fig. 2C). This result suggests the protective capacity of berberine against oxidative stress in lymphocytes. Berberine showed ABTS +ffree radical scavenging activity of $43.87 \%$ at $125 \mathrm{mg} \mathrm{ml}^{-1}$ in our previous study (Ryu et al., 2016). The result suggests that the inhibitory effect of berberine on oxidative DNA damage by triclosan might be due to its radical scavenging activity. Fig. $2 \mathrm{D}$ shows the inhibitory effect of resveratrol on triclosan-induced oxidative DNA damage. The olive tail moment with $1,3,5$ and $7 \mu \mathrm{g} \mathrm{m}^{-1}$ resveratrol treatment was approximately $36.7 \pm 4.17,19.3 \pm 2.41,8.2 \pm 0.34$ and 6.8 \pm 0.34 , respectively, while that at $6 \mu \mathrm{g} \mathrm{ml}^{-1}$ triclosan was $56.5 \pm$ 5.8. The olive tail moment of 5 and $7 \mu \mathrm{g} \mathrm{ml}^{-1}$ resveratrol-treated group was diminished close to the control value with a statistical significance.

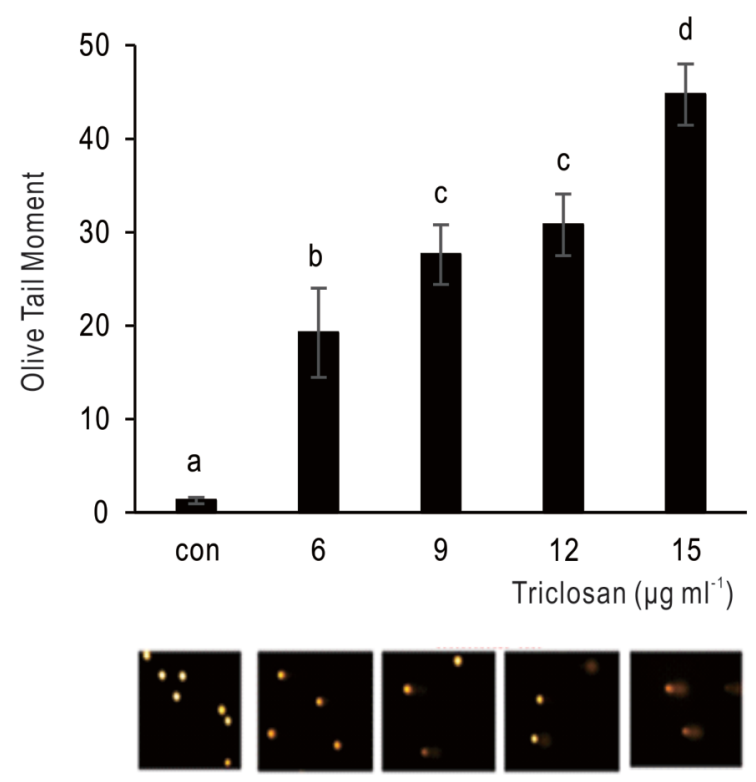

Fig. 1 : Triclosan-induced oxidative DNA damage measured by comet assay. Values not sharing the same letter are significantly different from one another $(p<0.05)$ according to Duncan's Multiple Range Test. 

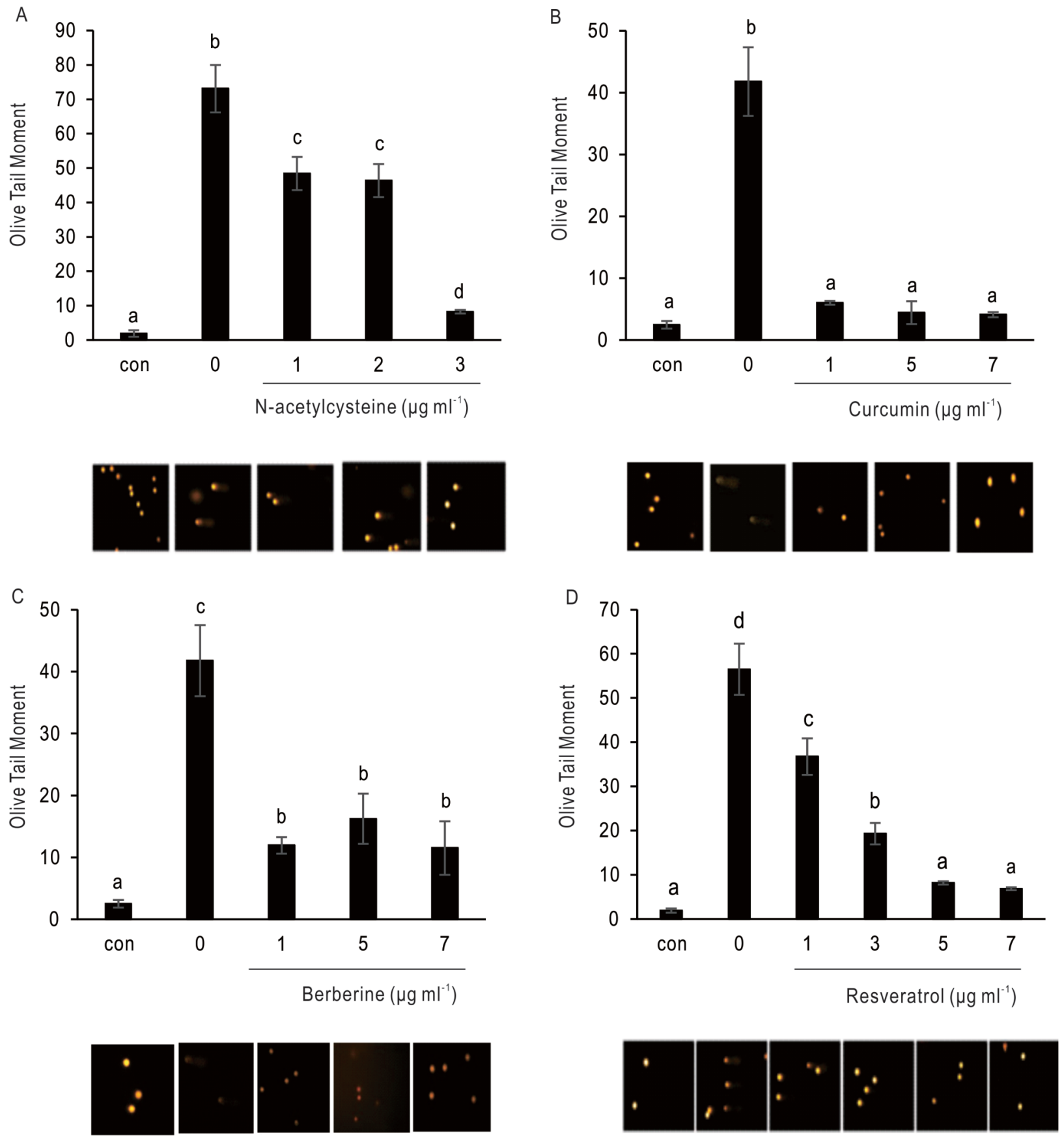

Fig. 2 : Suppressive effect of $\mathrm{N}$-acetylcysteine (A) curcumin (B) berberine (C) and resveratrol (D) on triclosan-induced oxidative DNA damage. Values not sharing the same letter are significantly different from one another $(p<0.05)$ according to Duncan's Multiple Range Test period.

Above results demonstrate the ameliorative effect of phytochemicals, such as curcumin, berberine and resveratrol on triclosan-induced oxidative DNA damage. Recently, comet assay has been applied not only for measuring DNA damage, but also in DNA repair studies. Most toxic compounds exert their toxicity via producing ROS, and it is generally accepted that the genotoxicity of toxic compounds can be reversed by antioxidants in vitro. Eukaryotic cells possess several repair systems for DNA damage before genome alterations occur, including base excision repair and nucleotide excision repair (Azqueta et al., 2014). Despite the mechanism underlying the mode of action of antioxidants implicated with cellular repair systems remains unclear, these 
phytochemicals could be developed as therapeutics for preventing DNA damage caused by triclosan via notable antioxidant properties.

\section{Acknowledgments}

This study was supported by Soonchunhyang University. We thank Lee JY and Jeon BG for their technical contributions.

\section{References}

Ajao, C., M.A. Andersson, V.V. Teplova, S. Nagy, C.G. Gahmberg, L.C Andersson, M. Hautaniemi, B. Kakasi, M. Roivainen and M. Salkinoja-Salonen: Mitochondrial toxicity of triclosan on mammalian cells. Toxicol. Rep., 7, 624-637 (2015).

Ao, J., T. Yuan, L. Ma, N. L. Gao, N. Ni and D. Li: Identification, characteristics and human exposure assessments of triclosan bisphenol-A and four commonly used organic UV filters in indoor dust collected from Shanghai, China. Chemosphere, 184, 575-583 (2017).

Azqueta, A., J. Slyskova, S.A. Langie, Gaivão I. O'Neill and A. Collins: Comet assay to measure DNA repair : Approach and applications. Front. Genet., 25, 288 (2014).

Dann, A.B. and A. Hontela: Triclosan: Environmental exposure, toxicity and mechanisms of action. J. Appl. Toxicol., 31, 285-311 (2011).

Datta, S., G. He, A. Tomilov, S. Sahdeo, M.S. Denison and G. Cortopassi: In vitro evaluation of mitochondrial function and estrogen signaling in cell lines exposed to the antiseptic cetylpyridinium chloride. Environ. Hlth. Perspect.,125, 087015 (2017).

De Flora, S., A. Izzotti, F. D'Agostini and R.M. Balansky: Mechanisms of $\mathrm{N}$-acetylcysteine in the prevention of DNA damage and cancer with special reference to smoking-related end-points. Carcinogenesis, 22, 999-1013 (2001).

Derochette, S., T. Franck, A. M.M, J. Ceusters, G. D.D, J.P. Lejeune, P. Neven and D. Serteyn: Curcumin and resveratrol act by different ways on NADPH oxidase activity and reactive oxygen species produced by equine neutrophils. Chem. Biol. Interact., 206, 186$193(2013)$

Dhupal, M., C.S. Kim, R.M.C. Ignacio, D. Tripathy and S.K. Kim: Effects of small black soybean product germinated with sulfur on immunoredox status in C57BL/6 mice. Mol. Cell. Toxicol.,13, 115-124 (2017).

Gao, S., C Li, L. Chen and X. Zhou: Actions and mechanisms of reactive oxygen species and antioxidative system in semen. Mol. Cell. Toxicol.,13, 143-154 (2017)

Grabacka, M.M., M. Gawin and M. Pierzchalska: Phytochemical modulators of mitochondria: The search for chemopreventive agents and supportive therapeutics. Pharmaceuticals (Basel), 7 , 913-942 (2014)

Halden, R.U.: On the need and speed of regulating triclosan and triclocarban in the United States. Environ. Sci. Technol., 48 3603-3611 (2014).

Kim, H.S., S.M. Lee, Y.J. Kim, W.H. Jang and Y.R. Seo: Integrative toxicogenomic analysis for elucidating molecular interference on DNAintegrity and repair system with underlying signaling networks in response to low-level lead acetate in rat liver model. Mol. Cell. Toxicol., 13, 179-188 (2017).

Kim, J.H., A.R. Ryu, M.J. Kang and M.Y. Lee: Berberine-induced changes in protein expression and antioxidant enzymes in melanoma cells. Mol. Cell. Toxicol., 12, 53-61 (2016).

Ko, J.W., S.H. Park, I.C. Lee, S.M Lee, I.S. Shin, S.S. Kang, C. J. Moon, S.H. Kim, J.D. Heo and J.C. Kim: Protective effects of garlic oil against 1,3-dichloro-2-propanol-induced hepatotoxicity: Role of CYP2E1 and MAPKs. Mol. Cell. Toxicol.,12, 185-195 (2016).

Marshall, N.B., E. Lukomska, C.M. Long, M.L. Kashon, D.D. Sharpnack, A.P. Nayak, K.L. Anderson, B.J. Meade and S.E. Anderson: Triclosan induces thymic stromal lymphopoietin in skin promoting Th2 allergic responses. Toxicol. Sci., 147, 127-39 (2015).

Nandhakumar, S., S. Parasuraman, M.M. Shanmugam, K.R. Rao, P. Chand and B.V. Bhat: Evaluation of DNA damage using single-cell gel electrophoresis (Comet Assay). J. Pharmacol. Pharmacother., 2,107-111 (2011).

Nilnumkhum, A., C. Punvittayagul, A. Chariyakornkul and R. Wongpoomcha: Effects of hydrophilic compounds in purple rice husk on AFB1-induced mutagenesis. Mol. Cell. Toxicol., 13, 171$178(2017)$.

Park, J.Y. and H.J. Jang: Anti-diabetic effects of natural products an overview of therapeutic strategies. Mol. Cell. Toxicol., 13, 1-20 (2017).

Rattan, S., C. Zhou, C. Chiang, S. Mahalingam, E. Brehm and J.A. Flaws: Exposure to endocrine disruptors during adulthood: Consequences for female fertility. J. Endocrinol., 233, R109-R129 (2017).

Rauf, A., M. Imran, H.A.R. Suleria, B. Ahmad, D.G Peters and M.S. Mubarak: A comprehensive review of the health perspectives of resveratrol. Food Funct., 8, 3879-3892 (2017).

Ruszkiewicz, J.A., S. Li, M.B. Rodriguez and M. Aschner: Is Triclosan a neurotoxic agent?. J. Toxicol. Environ. Hlth. B. Crit. Rev., 20, 104117 (2017).

Ryu, A.R., I.C. Bang, S.A. Lee and M. Y. Lee: The protective role of phytochemicals on $\mathrm{TiO}_{2}$ nanoparticles-induced DNA damage in lymphocytes. J. Environ. Biol., 37, 913-917 (2016).

Sadowska, A.M., B. Manuel-y-Keenoy and W.A. De Backer: Antioxidant and anti-inflammatory efficacy of NAC in the treatment of COPD: Discordant in vitro and in vivo dose-effects: A review. Pulm. Pharmacol. Ther., 20, 9-22 (2007).

Shim, J., L.M. Weatherly, R.H. Luc, M.T. Dorman, A. Neilson, R. Ng, C.H. Kim, P.J. Millard and J.A. Gosse: Triclosan is a mitochondrial uncoupler in live zebrafish. J. Appl. Toxicol., 36,1662-1667 (2016).

Singh, N.P., M.T. McCoy, R.R. Tice and E.L. Schneider: A simple technique for quantitation of low levels of DNA damage in individual cells. Exp. Cell Res., 175, 184-191 (1988).

Sreelatha, S., E. Dinesh and C. Uma: Antioxidant properties of Rajgira (Amaranthus paniculatus) leaves and potential synergy in chemoprevention. Asian Pac. J. Cancer Prev., 13, 2775-2780 (2012).

Szychowski, K.A., A. Wnuk, M. Kajta and A.K. Wójtowicz: Triclosan activates aryl hydrocarbon receptor (AhR)-dependent apoptosis and affects Cyp1a1 and Cyp1b1 expression in mouse neocortical neurons. Environ. Res., 151, 106-114 (2016).

Teplova, V.V., K.N. Belosludtsev and A.G. Kruglov: Mechanism of triclosan toxicity: Mitochondrial dysfunction including complex II inhibition, superoxide release and uncoupling of oxidative phosphorylation. Toxicol. Lett., 275, 108-117 (2017).

Verslycke, T., D.B. Mayfield, J.A. Tabony, M. Capdeviell and B. Slezak: Human health risk assessment of triclosan in land-applied biosolids. Environ. Toxicol.Chem., 35, 2358-2367 (2016)

Weatherly, L.M., J. Shim, H.N. Hashmi, R.H. Kennedy, S.T. Hess and J.A Gosse: Antimicrobial agent triclosan is a proton ionophore uncoupler of mitochondria in living rat and human mast cells and in primary human keratinocytes. Appl. Toxicol., 36, 777-789 (2015).

Yueh, M.F., K. Taniguchi, S. Chen, R.M. Evans, B.D. Hammock, M. Karin and R.H. Tukey: The commonly used antimicrobial additive triclosan is a liver tumor promoter. Proc. Natl. Acad. Sci. U.S. A.,111, 17200-17205 (2014). 